\title{
A relação mãe-criança durante o atendimento odontológico: contribuições da análise do comportamento
}

\author{
Mother-child relations during dental \\ care: Behavior analysis \\ contributions
}

\author{
Olivia Justen BRANDENBURG \\ Maria Luiza MARINHO-CASANOVA²
}

\begin{abstract}
Resumo
O presente artigo visou analisar a interação entre mães e crianças durante o atendimento odontológico. Participaram cinco pacientes (idade entre 2 e 7 anos) com seus acompanhantes. Os atendimentos foram filmados e observadores registraram os comportamentos infantis e maternos. Dentre os dados quantitativos, houve maior índice de não colaboração associado ao menor índice de interação materna. A análise qualitativa dos dados, feita pela análise funcional, indicou que as mães podem exercer função de estímulos antecedentes e consequentes para o comportamento infantil no atendimento odontológico e podem exercer função de variável histórica pela modelagem de comportamentos de autocontrole e de seguir regras. Analisando as contingências, é possível prever e controlar o comportamento. Pais podem ser instruídos e treinados para agirem de forma mais adequada durante o atendimento odontológico, em benefício da saúde de seu filho.
\end{abstract}

Unitermos: Análise funcional; Criança; Odontopediatria; Relações mãe-filho.

\begin{abstract}
This article intended to analyze the interaction between mother's and children's behaviors during dental care. The subjects were 5 dental patients (aged between 2 and 7 years) with their mothers. Dental sessions were videotaped, observers recorded child's and dentist's behavior. Quantitative analysis showed the higher rates of non-cooperation associated to the least interactive mother. Qualitative analysis, through functional analysis, indicated that the mothers might play a role as antecedents and as consequences for children's behavior in dental care; also, they can exert the function of historical variable by training self-controlled and rule-following behavior. Analyzing the contingencies, it is possible to predict and control behavior. Parents can be instructed and trained to conduct themselves more properly for the benefit of their child's health.
\end{abstract}

Uniterms: Functional analysis; Child; Pediatric dentistry; Mother-child relations.

$\checkmark v$

1 Faculdade de Administração, Ciências Contábeis, Educação e Letras, Curso de Psicologia. Av. Vicente Machado, 156, Centro, 80420-010, Curitiba, PR, Brasil. Correspondência para/Correspondence to: O. J. BRANDENBURG. E-mail:<oliviaozi@yahoo.com.br>.

2 Universidade Estadual de Londrina, Curso de Psicologia, Departamento de Psicologia Geral e Análise do Comportamento. Londrina, PR, Brasil.

Artigo elaborado a partir da dissertação de O.J. BRANDENBURG, intitulada "Análise da interação entre a mãe e a criança durante atendimento odontológico". Universidade Estadual de Londrina, 2008.

Apoio: Coordenação de Aperfeiçoamento de Pessoal de Nível Superior. Demanda Social: 2008. 
A atuação do psicólogo junto ao comportamento infantil envolve sempre o trabalho com pais. $\mathrm{Na}$ área da saúde, tanto no âmbito médico quanto no odontológico, não é diferente. Ao tratar da promoção da saúde infantil, da prevenção de doenças ou da adesão ao tratamento, é necessário que o profissional compreenda o papel dos pais e busque reeducar o comportamento dos mesmos para que possa atingir objetivos que tragam benefícios para a criança.

A adesão ao tratamento no contexto odontológico inclui submeter-se a tratamentos profiláticos e cirúrgicos. No entanto, algumas crianças dificultam o atendimento do dentista ao apresentarem comportamentos como choro, gritos, movimentos corporais. Estes são denominados comportamentos não colaborativos por atrasarem ou impedirem o procedimento odontológico, exigindo do dentista alteração da rotina da consulta (Possobon, Moraes, Costa Júnior \& Ambrosano, 2003).

O estudo do comportamento de colaboração infantil durante o atendimento odontológico corresponde a um dos grandes focos da literatura científica de odontopediatria. Dentre os fatores que afetam tal comportamento, tem-se investigado o comportamento dos pais, que aparece nas pesquisas como uma variável relevante (Allen, Huftless \& Larzelere, 2003; Fenlon, Dobbs \& Curzon, 1993; Kotsanos, Arhakis \& Coolidge, 2005; Marzo, Campanella, Albani \& Gallusi, 2003; Robey, 2006; Tomita, Costa Junior \& Moraes, 2007).

Sabendo que os pais preferem estar presentes na consulta odontológica durante o tratamento de seu filho (Araújo, Silveira, Mello, Caregnato \& Dal'Asta, 2010), eles podem receber orientações sobre como agir para facilitar a colaboração infantil. A literatura a esse respeito já apresenta a possibilidade de intervenção com pais, como mostra o exemplo da pesquisa de Xia e Zhang (2012), que treinou pais para ajudarem o filho na colaboração com o dentista. Esses pais treinados, em comparação com o grupo controle, apresentaram-se mais relaxados e usaram linguagem mais positiva durante a consulta; como resultado, seus filhos colaboraram mais.

Percebe-se, então, a relevância de investigações a respeito do papel dos pais sobre o comportamento de colaboração infantil no atendimento odontológico.

630 Por envolver aspectos comportamentais, esse é um campo de estudo que se beneficia da parceria entre Psicologia e Odontologia, como ressaltado por Cardoso e Loureiro (2008).

A Análise do Comportamento tem muito a contribuir na explicação do comportamento não colaborativo infantil, como já demonstrado nos estudos de Brandenburg e Haydu (2009); Fioravante e Marinho- Casanova (2009); Fioravante, Soares, Silveira e Zakir (2007); Moraes, Sanchez, Possobon e Costa Júnior (2004); Rolim, Moraes, César e Costa Júnior (2004). Esses autores focaram na análise dos comportamentos da criança e do dentista.

Assim, o presente artigo pretende trazer maiores contribuições ao analisar o comportamento das mães relacionado ao da criança no contexto odontológico, sob o ponto de vista analítico-comportamental. Para isso, será apresentada de forma breve a visão teórica dessa ciência psicológica, para, na sequência, discutir os dados da literatura sobre os pais no contexto odontopediátrico, tornando-se possível descrever o método e os dados encontrados na presente pesquisa.

Os comportamentos de não colaboração da criança são, geralmente, atribuídos a fatores internos ao indivíduo, como medo, ansiedade, traumas, condições fisiológicas, havendo menos atenção aos eventos presentes no ambiente odontológico (Brandenburg \& Haydu, 2009). Para o analista do comportamento, quando se procura dentro do organismo uma explicação para o que o indivíduo faz, deixa-se de investigar as variáveis passíveis de análise científica, as quais estão fora do organismo: no ambiente atual ou histórico (Skinner, 1953/1993).

Portanto, analistas do comportamento procuram explicar a não colaboração infantil no consultório do dentista por meio da identificação das relações funcionais entre o comportamento da criança e as variáveis ambientais, ou seja, por meio da análise funcional. Esta análise de relações inclui a ocasião em que a resposta ocorre (antecedente), a própria resposta e as consequências ambientais (Skinner, 1953/1993).

As condições ambientais que podem ter função sobre esse comportamento infantil são inúmeras. Moraes e Pessotti (1985) citam, como exemplos de condições antecedentes para o comportamento das crianças, os eventos ocorridos na sala de espera (como ouvir 
histórias e esperar muito pela consulta), ruídos e odores fortes na sala de atendimento e instruções fornecidas pelo dentista; como exemplos de condições consequentes, os autores citam as decorrências da intervenção (como alívio da dor e recuperação estética) e os comportamentos do dentista de reforçar ou punir a criança. Acrescenta-se a essas variáveis antecedentes e consequentes o comportamento dos pais. Pesquisas empíricas têm investigado o comportamento dos pais no ambiente imediato do consultório odontológico ou no ambiente histórico infantil; seguem as descrições de algumas delas.

\section{Pesquisas sobre comportamento dos pais relacionados ao comportamento da criança no atendimento odontológico}

O efeito dos comportamentos parentais sobre a colaboração dos filhos na sala de consulta odontológica é uma preocupação que vem de longa data. Wright, Alpern e Leake (1973) citam autores discutindo esse tema desde o final do século XIX e início do século XX. Algumas das variáveis estudadas nos pais são a ansiedade, o medo e o stress. Johnson e Baldwin (1969), Koenigsberg e Johnson (1972) e Wright et al. (1973) relataram que os maiores índices de ansiedade materna se correlacionaram de forma significativa e positiva com a não colaboração infantil. Robey (2006) notou que os altos índices de stress observados nas crianças durante o tratamento odontológico estavam correlacionados, de forma significativa, com maiores escores de medo do dentista e ansiedade relatados pelos pais ou mães. As análises realizadas por Cardoso e Loureiro (2008) observaram que as crianças menos colaboradoras estavam acompanhadas por mães que apresentaram maiores indicadores de medo odontológico e de stress.

Outro fator de interesse científico são as práticas educativas parentais, como mostram Venham, Murray e Gaulin-Kremer (1979) e Allen et al. (2003). Sobre a investigação de práticas educativas parentais, Venham et al. (1979). Encontraram correlação significativa entre menores índices de ansiedade infantil e organização do ambiente familiar, com mães responsivas que impunham limites e faziam uso amplo de reforçamento e punição. Já as crianças ansiosas na consulta odontológica tinham mães permissivas, irritadas e com pouca autoconfiança, que evitavam punições ou limitações. Este último dado corrobora um resultado da pesquisa de Allen et al. (2003): dos pais avaliados, aqueles que cediam muito e estabeleciam poucos limites tiveram maior probabilidade de ter crianças não colaboradoras no dentista.

Embora seja importante ressaltar o fato de os estudos serem correlacionais e parte dos dados ter sido coletada de forma indireta, a relevância dessas pesquisas descritas encontra-se no fato de indicarem relação entre o comportamento da criança na consulta odontológica e comportamentos parentais fora do consultório. A forma como a criança reage no dentista pode depender, entre outros fatores, de sua relação com os pais, que ensinam diferentes repertórios necessários para enfrentar ou não um atendimento odontológico.

Assim, o estudo dos comportamentos parentais, como ansiedade e medo ou práticas educativas, é interessante por possibilitar a compreensão do controle do comportamento infantil por variáveis que não necessariamente estão presentes no atendimento odontológico. O comportamento atual interage com contingências presentes e também com as passadas, pois sua explicação envolve variáveis históricas (Chiesa, 1994). Portanto, a colaboração e a não colaboração da criança no dentista não estão apenas sob controle de eventos atuais do momento da consulta: a história individual aumenta a probabilidade de a criança interagir com certos estímulos ou não.

O comportamento dos pais durante a consulta odontológica também tem sido investigado para explicar o comportamento infantil de colaborar ou não com o dentista. São poucas as pesquisas encontradas na literatura a respeito e não há consenso nos resultados.

Os resultados de Fenlon et al. (1993) mostraram que a presença ou a ausência dos pais das 32 crianças (de 4 a 12 anos) analisadas durante o atendimento odontológico não alterou de forma significativa o comportamento infantil na consulta. Correlação significativa apareceu na comparação entre as idades: as crianças menores apresentaram maiores índices de comportamento negativo do que as mais velhas, independentemente do grupo ao qual pertenciam. Os autores buscaram explicação no fato de as crianças mais novas ainda não terem experiências anteriores para lidar com 
ambiente estranho e, portanto, terem pouco repertório de enfrentamento.

Na pesquisa realizada por Marzo et al. (2003), 200 crianças foram divididas em dois grupos: no Grupo 1 os pais estavam ausentes e no Grupo 2 os pais estavam presentes. Nos resultados, o Grupo 1 teve 89\% das crianças totalmente cooperativas contra $63 \%$ no Grupo 2; além disso, 8\% das crianças do Grupo 2 não voltaram para qualquer cuidado odontológico mais profundo, contra 1\% no Grupo 1. Assim, concluiu-se que a visita odontológica inicial é melhor quando os pais estão ausentes.

A presença ou a ausência dos pais foi manipulada na pesquisa de Kotsanos et al. (2005). Em primeira consulta, 85 crianças não colaborativas, com idade entre 2 e 8 anos, tiveram seus pais retirados da sala de atendimento, os quais retornaram somente quando a criança passou a colaborar. Como resultado, observou-se o sucesso da estratégia na redução da não colaboração em 94\% dessas crianças.

Os dados dessas três pesquisas mostram que os resultados não são claros a respeito do controle que os pais exercem sobre o comportamento da criança durante o atendimento odontológico. Na pesquisa de Kotsanos et al. (2005), comportamentos não colaborativos diminuíram nas consultas em que os pais se retiraram da sala de atendimento. Pode-se considerar que a ausência parental funcionou como punição para comportamentos não colaborativos da criança por esses diminuírem após a saída dos pais; e o retorno dos pais para a sala pode ter exercido função reforçadora positiva para a colaboração da criança. Na pesquisa de Marzo et al. (2003), não ficou esclarecido qual tipo de controle os pais exerceram sobre o comportamento da criança, ao indicar que filhos com pais ausentes se mostraram mais colaboradores do que aqueles com pais presentes na sala. Os comportamentos dos pais poderiam funcionar tanto como antecedentes quanto como consequentes para a criança. Por fim, na pesquisa de Fenlon et al. (1993), os pais pareceram não exercer controle sobre o comportamento infantil, já que a maioria colaborou, independentemente da presença ou ausência de seus pais.

Apesar dos esforços dos pesquisadores em entender o efeito da presença dos pais no comporta-

632 mento da criança em atendimento odontológico, iden- tificar respostas emitidas pela criança de acordo com a ausência/presença traz poucos esclarecimentos sobre o controle dos pais sobre seus filhos nesse contexto. Faz-se necessário entender porque isso ocorre e descrever quais são os comportamentos parentais apresentados durante o atendimento odontológico que afetam a colaboração e a não colaboração dos filhos.

Nesse sentido, a pesquisa de Tomita et al. (2007) traz muitas contribuições, ao descrever os comportamentos de dez mães na observação do atendimento a crianças de três anos não colaboradoras. Verificou-se que o aumento da colaboração da criança relacionou-se tanto com o aumento de comportamentos afetivos das mães, quanto com a diminuição do "conter a criança" e com a diminuição do "segurar a mão". Considerou-se que o afeto materno interferiu na colaboração do filho até certo ponto, pelo fato de os procedimentos odontológicos passarem a exercer maior controle sobre o comportamento da criança. De forma geral, o trabalho dessa autora expõe quais comportamentos as mães apresentam durante a consulta odontológica do filho e como esses comportamentos variam de acordo com o procedimento odontológico e de acordo com o comportamento da criança.

Enfim, com todas as pesquisas citadas, obtiveram-se indicações de que o comportamento dos pais exerce influência sobre o comportamento do filho na consulta odontológica. Apesar do reconhecimento desse impacto, ainda não foi esclarecido como ocorre esse processo (Shiota, 2004). Nesse sentido, a pesquisa que resultou no presente artigo teve essa proposta, na medida em que buscou analisar a interação entre mães e crianças durante o atendimento odontológico do filho, com o objetivo de investigar o comportamento da mãe como uma das variáveis controladoras do comportamento infantil de não colaboração.

\section{Método}

\section{Participantes}

Participaram cinco crianças, sendo duas do sexo feminino e três do sexo masculino. Para facilitar o relato dos dados, cada criança recebeu um nome fictício: Pedro tinha sete anos, Vitória tinha cinco anos, Alice 
tinha três anos, Davi e Lucas tinham dois anos. Todos estavam acompanhados de suas mães, com exceção de Vitória, que estava com sua avó.

A coleta de dados foi realizada no pronto-socorro de uma clínica universitária de odontologia que atende gratuitamente pacientes de até seis anos de idade. Excepcionalmente pode ocorrer, neste serviço, o atendimento a crianças com sete anos, como foi o caso de Pedro, participante desta pesquisa.

\section{Instrumentos}

No pronto-socorro odontológico da clínica, as crianças são atendidas por duplas de profissionais de odontologia que cursam especialização ou fazem residência em Odontopediatria. Sete desses profissionais, todas do sexo feminino, compuseram as equipes que atenderam às crianças participantes da pesquisa. A conduta de todas as dentistas seguiu um determinado padrão, de acordo com o treinamento que receberam na instituição, como: fazer "mágica" para a cadeira levantar e deitar, usar a técnica"conte-mostre-faça" e conversar com a criança. Ainda segundo o treinamento, se a criança estiver agitada pode-se utilizar algum tipo de restrição física, como o abridor de boca, a retenção de movimentos por parte de outra pessoa que segura o corpo da criança ou o pacote pediátrico (restrição física total em que a criança fica envolvida com um lençol).

Foram utilizados filmadora, tripé, televisão e videocassete, destinados à gravação das interações entre mães e filhos na clínica odontológica para posterior análise. Após a fase de registro dos comportamentos filmados e as análises dos dados, as fitas com as gravações realizadas foram destruídas.

\section{Procedimentos}

Primeiramente, o projeto de pesquisa foi submetido ao Comitê de Ética em Pesquisa envolvendo seres humanos da Universidade Estadual de Londrina, tendo sido aprovado (Parecer no 268/06 em 30 de outubro de 2006). Todos os participantes assinaram um Termo de Consentimento Livre e Esclarecido antes de sua inclusão na amostra. Os responsáveis pela criança e as dentistas autorizaram a realização da pesquisa com filmagem das sessões.
Para selecionar as cinco díades participantes, foram estabelecidos os seguintes critérios: criança com idade igual ou maior que dois anos, atendidas no pronto-socorro, com necessidade de tratamento odontológico cirúrgico (pulpectomia ou exodontia), que pudesse ser observada em duas consultas.

A filmagem era iniciada quando a criança se sentava na cadeira odontológica e continuava até o término da consulta. Os comportamentos das crianças e de suas mães foram gravados em dois atendimentos para posterior observação e análise, sem que houvesse nenhum tipo de interferência por parte da pesquisadora na consulta.

\section{Análise dos dados}

Os comportamentos das crianças e de suas mães foram diretamente observados, posteriormente registrados e analisados de forma quantitativa e qualitativa, por meio da análise funcional do comportamento.

Para a análise quantitativa, os comportamentos de não colaboração da criança e os comportamentos interativos da mãe foram categorizados. As categorias para as mães foram: a) interação verbal com a criança, como elogio, consolo, promessa de recompensa, distração, instrução; b) interação gestual com a criança, mediante contatos físicos como tocar as pernas, braços, mãos, rosto, excluindo restrição física. Seguem as categorias definidas para as crianças: a) movimento do corpo ou da cabeça: qualquer movimento de corpo e/ou cabeça que ocorresse no início ou durante um procedimento odontológico e que atrapalhasse a atuação do dentista, mas sem interrompê-lo, concomitante ou não com choro (Possobon et al., 2003), excluindo movimentos em resposta às instruções do dentista; b) choro e reclamações: qualquer choro ou reclamação, grito e gemido durante ou entre procedimentos odontológicos, excluindo reclamações em resposta a questões do dentista; quando a criança chorava e gritava ao mesmo tempo foram contabilizados dois comportamento no intervalo.

Os comportamentos foram registrados em intervalos de 15 segundos. As categorias "a" e "b" da criança foram somadas, assim como as categorias "a" e "b" da mãe foram somadas, por minuto, permitindo a 
elaboração dos gráficos de cada díade. Além disso, realizou-se o cálculo da frequência do comportamento por minuto (divisão do número de comportamentos emitidos pelo tempo da consulta) para comparação entre as díades.

\section{Resultados e Discussão}

Os dados das díades podem ser observados nas Figuras 1 a 4. Nota-se que não foi apresentado o gráfico dos comportamentos de Pedro, por não ter apresentado resposta de não colaboração nas consultas. A partir dos dados das figuras, percebe-se que houve diferença entre as crianças e diferença entre as mães. Como o objetivo desta pesquisa foi analisar o compor-tamento da mãe como uma variável que controla o comportamento de não colaboração do filho na consulta odontológica, o ponto de partida foi o comportamento das crianças. Será apresentada, a seguir, a análise funcional do comportamento de não colaboração, com base nos dados das figuras apresentadas, com discussão sobre as diferentes variáveis que afetam tal comportamento, sendo uma delas o comportamento materno.

\section{Análise funcional do comportamento de não colaboração da criança}

Pelas Figuras 1 a 4, pode-se verificar que o choro e os movimentos corporais apresentados pelas crianças estavam, em parte, sob controle do procedimento odontológico em ação. Certamente, tal procedimento pode envolver estimulação aversiva. O estímulo aversivo é aquele que reforça comportamentos que o removem (Skinner, 1953/1993) ou pune comportamentos que o produzem, além de eliciar comportamentos emocionais como medo e ansiedade (Catania, 1999).

Assim, compreende-se que alguns eventos na consulta odontológica, para Vitória, Alice, Davi e Lucas, caracterizaram-se como estimulações aversivas que eliciaram e evocaram comportamentos de choro e movimentos corporais. Evidências experimentais indicam que o procedimento odontológico exerce função de estímulo aversivo para algumas crianças (Allen, K.D., Loiben, Allen S.J. \& Stanley, 1992; Allen, Stark, Rigney, Nash \& Stokes, 1988; Allen \& Stokes, 1987; O'Callaghan, Allen \& Powell, 2006). Alice, Davi e Lucas emitiram comportamentos como não abrir a boca, mexer a cabeça ou morder o dedo da dentista, atra-

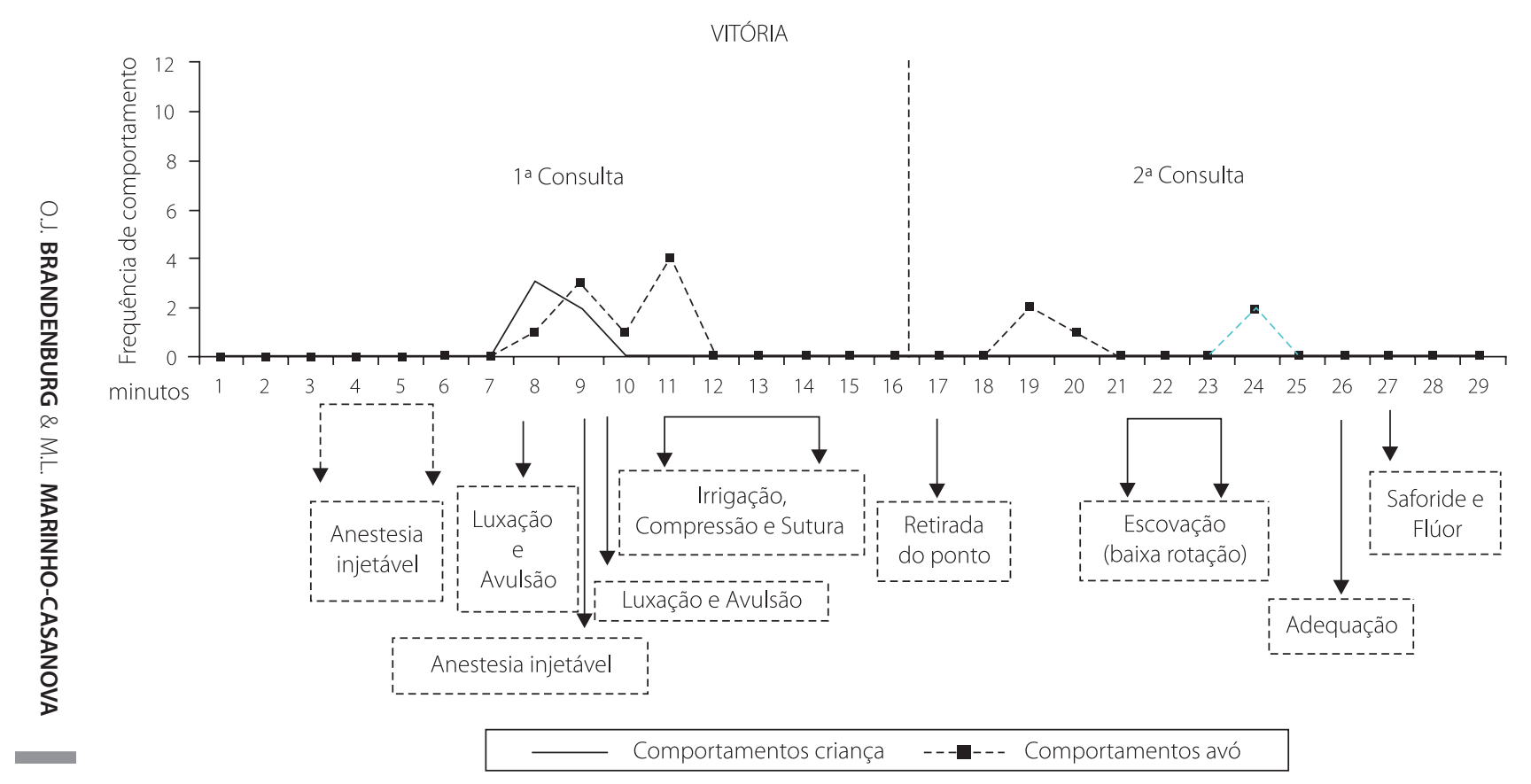

634 Figura 1. Comportamentos de Vitória e de sua avó ao longo das duas consultas odontológicas. Londrina (PR), 2008. 


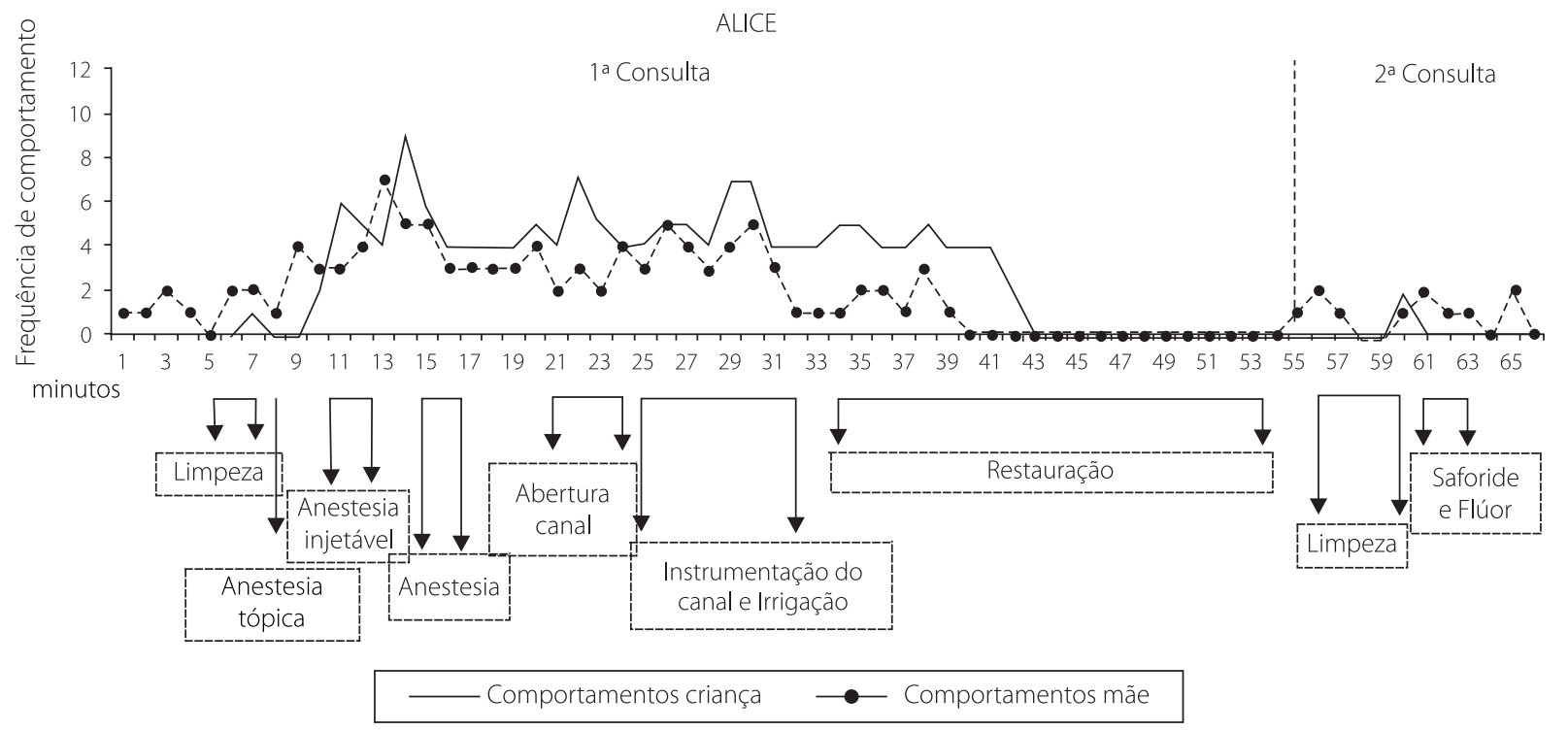

Figura 2. Comportamentos de Alice e de sua mãe ao longo das duas consultas odontológicas. Londrina (PR), 2008.

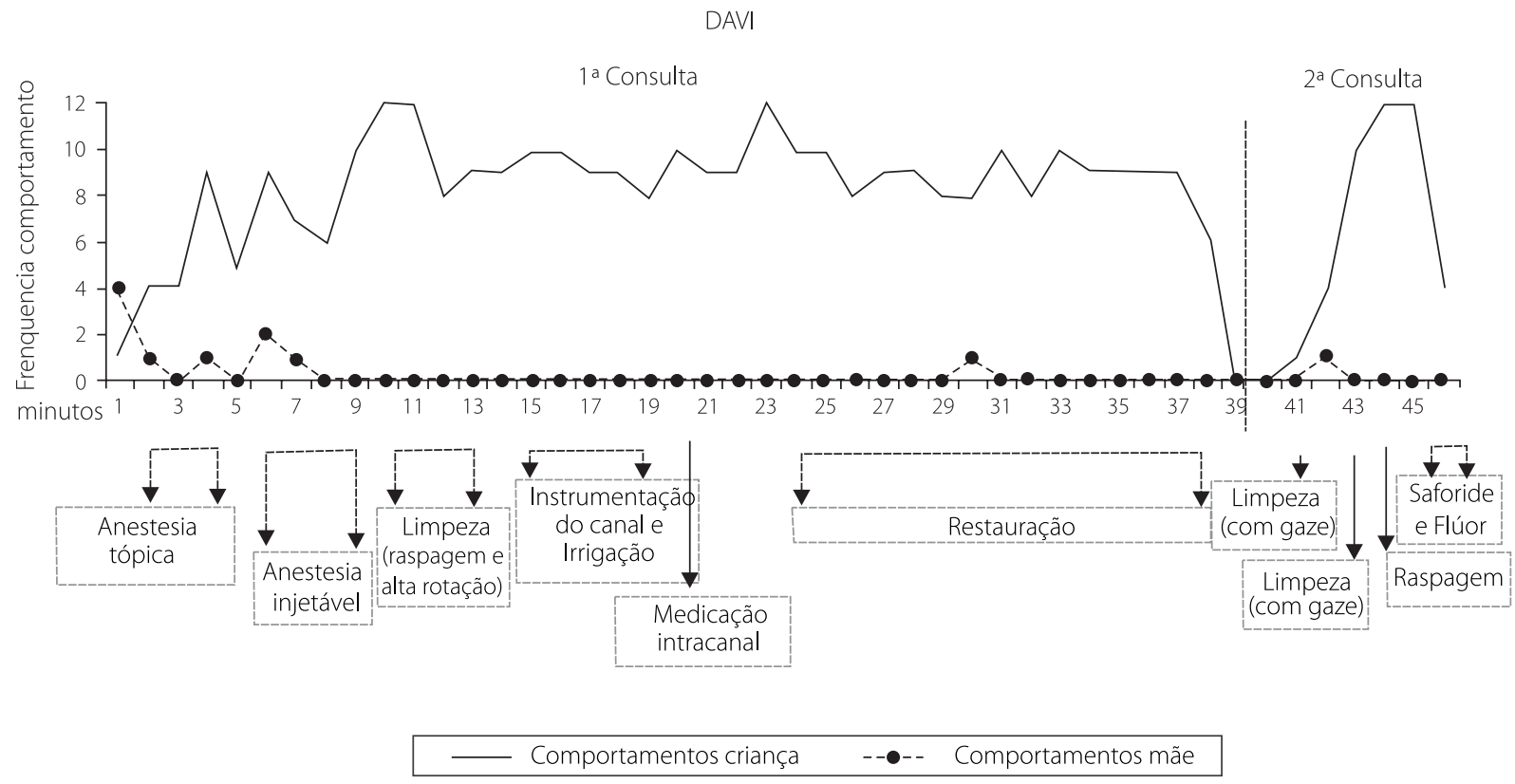

Figura 3. Comportamentos de Davi e de sua mãe ao longo das duas consultas odontológicas. Londrina (PR), 2008.

sando os procedimentos odontológicos e exigindo algum tipo de restrição física, sendo esta o abridor de boca, uma auxiliar segurando ou o pacote pediátrico. Nota-se que Davi foi a criança que mais se movimentou, durante mais tempo, mesmo estando imobilizado pelo pacote pediátrico.
Os comportamentos de não colaboração tiveram frequências alteradas em função do tipo de procedimento, como anestesia ou uso de alta rotação, conforme aparece nas Figuras 1 a 4. Vitória, por exemplo, colaborou na maior parte do tempo, chorou apenas durante a luxação e avulsão dentária. Dados de pes- 


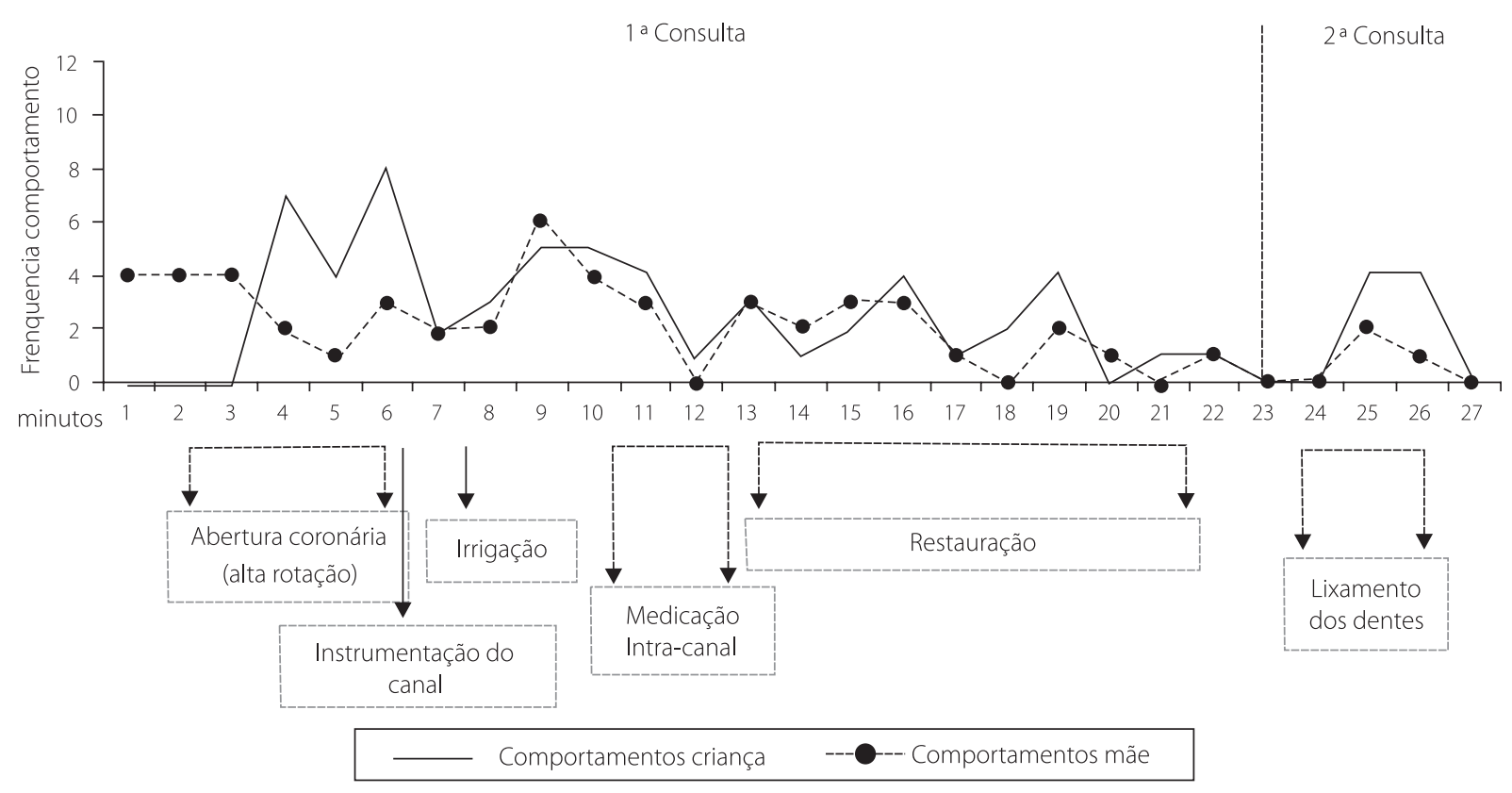

Figura 4. Comportamentos de Lucas e de sua mãe ao longo das duas consultas odontológicas. Londrina, (PR), 2008.

quisa confirmam que, durante os procedimentos classificados como invasivos, ocorre aumento da manifestação de stress das crianças, acompanhado do aumento significativo da dificuldade de colaboração por parte delas (Cardoso \& Loureiro, 2008).

No entanto, os estímulos presentes nos procedimentos odontológicos não são necessariamente aversivos para todas as crianças. Para compreender esse fato, deve-se considerar a diferença de idade. As crianças mais velhas, Pedro e Vitória (com sete e cinco anos, respectivamente), foram as mais colaboradoras. As mais novas, Alice, com três anos, e Davi e Lucas, ambos com dois anos, foram as menos colaboradoras. A diferença de idade pode ser um fator que explique a diferença entre as crianças, e por isso será analisado a seguir.

Como nos resultados da pesquisa ora descrita, a literatura apresenta dados de menos colaboração por parte de crianças mais novas (Allen et al., 2003; Wright et al., 1973). Gross, Stern, Levin, Dale e Wojnilower (1983) afirmaram que crianças mais novas apresentavam maiores índices de choro, agressão e resistência antes e durante o procedimento, e Robey (2006) verificou maior índice de stress nos pacientes mais novos. Diante

636 dos dados de maior índice de comportamentos nega- tivos entre as crianças mais novas, Fenlon et al. (1993) buscaram atribuir este fenômeno ao fato de crianças menores terem poucas experiências anteriores em lidar com ambiente estranho e pouco repertório de enfrentamento.

Concordando com a explicação de Fenlon et al. (1993), a análise funcional dos comportamentos das três crianças mais novas da presente amostra pode contribuir para compreender a não colaboração delas. Considera-se que existe um déficit de comportamentos de autocontrole e de seguir regras no repertório de Alice, Davi e Lucas, dificultando o enfrentamento da situação de atendimento odontológico.

O comportamento de controlar o próprio comportamento ocorre em algumas situações, dentre elas, quando se aceita um evento aversivo relativamente pequeno e imediato, e esta aceitação leva a consequências distantes no tempo, como um reforçador maior, ou evita um aversivo maior (Catania, 1999). Provavelmente, Pedro e Vitória suportaram eventos aversivos pequenos durante os procedimentos odontológicos (ficar imóvel e com boca aberta) e isso levou a um reforçador maior (elogio dos pais, dentes saudáveis) ou evitou um aversivo maior (críticas, imobilização, 
dor de dente). Além disso, no caso de Vitória, parece ter-se estabelecido conflito entre consequências reforçadoras e punitivas, necessário para a ocorrência de autocontrole (Nico, 2001). Nos momentos em que a criança passava pelos procedimentos potencialmente aversivos, como anestesia e luxação, a avó elogiava a criança, fornecendo reforçadores.

Por outro lado, observa-se que Alice, Davi e Lucas não apresentaram comportamentos de autocontrole e, de fato, não se espera que crianças com dois e três anos se comportem sob o efeito de consequências atrasadas. Se, para ocorrer o autocontrole, é necessário que o estímulo aversivo imediato seja pequeno e o reforçador e o aversivo atrasados sejam maiores, para essas três crianças mais novas o evento aversivo imediato teve valor maior. Pôde-se observar isso pelo fato de os três terem recebido, durante o atendimento, promessas de brindes ao final da consulta, reforçadores atrasados, e isso não ter afetado seu comportamento. As mães de Alice e de Lucas deram, por diversas vezes, respostas verbais de consolo e distração. A mãe de Lucas, por exemplo, falava sobre assuntos de que seu filho gostava, como a lanterna que era parecida com a luz da cadeira do dentista. A mãe de Alice forneceu seu exemplo, elogiou e, em alguns momentos, ofereceu sua mão para a filha apertar no momento de dor. Quando Alice chorou e gritou muito, a mãe ameaçou sair da sala. Foram tentativas que diminuíram o choro ou movimentos dos filhos, mas não foram estímulos fortes o suficiente na competição com os aversivos imediatos do procedimento odontológico para eliminar as respostas de não colaboração. Trata-se de um conhecimento importante, pois, entendendo que a criança está muito mais sob controle de consequências imediatas, os reforçadores imediatos devem ser utilizados, inclusive para a criança aprender a se controlar.

Um fator que contribui para explicar a ausência do conflito necessário para o estabelecimento do autocontrole é a falta de repertório em seguir regras. Trata-se de um repertório necessário para que outras aprendizagens aconteçam, incluindo a de autocontrole. Vitória e Pedro, por exemplo, seguiram as instruções das dentistas, o que indica um histórico de modelagem do comportamento de seguir regras. Assim, o reforço positivo de obedecer às instruções da dentista ou da mãe pode ter controlado o comportamento dessas crianças. Compreende-se que dentes saudáveis são reforçadores muito atrasados, o que diminui sua eficiência (Catania, 1999). Reforçadores imediatos, como a aprovação por obediência, podem ter adquirido maior valor na história dessas crianças, o que é favorável para competir com o possível controle aversivo aos procedimentos odontológicos e proporcionar o autocontrole.

Por outro lado, as crianças mais novas, de dois e três anos, não apresentaram o mesmo repertório de seguir regras. As mães dessas crianças forneciam instruções de ficar quieto, não mexer, abrir a boca, que nem sempre eram seguidas. A mãe de Davi deu apenas uma instrução no início da segunda consulta e as dentistas instruíam o tempo todo, mas Davi não obedecia. Com isso, essas três crianças parecem ainda não ter o treino para apresentar repertório de seguir regras. A importância do uso de instruções como treino de seguir regras está no favorecimento de tornar o comportamento controlado por consequências atrasadas (Reis, Teixeira \& Paracampo, 2005).

\section{O comportamento das mães como uma variável controladora dos comportamentos infantis de não colaboração}

Nas análises realizadas até o momento sobre a não colaboração infantil, percebe-se que as respostas das mães podem funcionar como estímulos antecedentes (instruções, prometer recompensa, tentativa de distrair mudando o foco de atenção, fornecer exemplo) e como estímulos consequentes (elogio, consolo, ameaças de sair). As mães de Alice e de Lucas, que apresentaram esses estímulos, facilitaram o desenvolvimento de autocontrole e de seguir regras nas crianças. A mãe de Pedro e a avó de Vitória não precisaram fazer uso disso, já que as crianças colaboraram. Já a mãe de Davi não emitiu esse tipo de comportamento enquanto havia demanda de seu filho para isso. Com essas análises do comportamento infantil, percebe-se a importância do comportamento materno para a compreensão da colaboração e da não colaboração por parte da criança. São os pais, normalmente, os responsáveis pela modelagem de repertórios como autocontrole e seguimento de regras.

Assim, há indícios de que o comportamento materno pode influenciar o comportamento infantil durante $\mathrm{o}$ atendimento odontológico. Certamente, 
deve-se considerar que a pesquisa não se caracterizou como experimental, para que se possa estabelecer uma relação de causalidade - o que pode demonstrar uma limitação metodológica. No entanto, o ponto forte em buscar dados coletados diretamente, e não por relato, favorece a confiança nos resultados, que, analisados de forma quantitativa e qualitativa, mostraram o comportamento materno como um fator relevante na explicação do comportamento infantil em consulta odontológica.

A Figura 5, a seguir, facilita a comparação entre as díades. Os dados desta resumem aqueles demonstrados nas Figuras 1 a 4 . As duas crianças mais velhas, com baixos valores de comportamento não colaborativo, apresentaram dados de mães com baixa frequência de comportamentos interativos. Para as crianças mais novas, aparece um contraste ao comparar as díades. A mãe da criança menos colaborativa, Davi, foi a que apresentou menos interação com a criança durante as duas consultas de atendimento odontológico. A comparação entre Alice e Davi é interessante: a mãe de Alice apresentou maior índice de interação que a mãe de Davi, e Alice apresentou menor índice de comportamentos não colaborativos que Davi. Os dados das cinco díades apontam diferenças no comportamento infantil de acordo com a interação da mãe com o filho.

Os dados de Tomita et al. (2007) também mostraram que os comportamentos maternos afetaram, em parte, o comportamento infantil, em razão da interferência do procedimento odontológico. Assim, é certo que existe alta probabilidade de o comportamento infantil ficar sob controle do procedimento odontológico, mas os dados aqui descritos mostram que o comportamento materno também pode afetar o comportamento da criança. Os comportamentos de usar palavras de conselho, apoio, consolo e distração, ou os modos de tocar a criança para acariciar e acalmar,

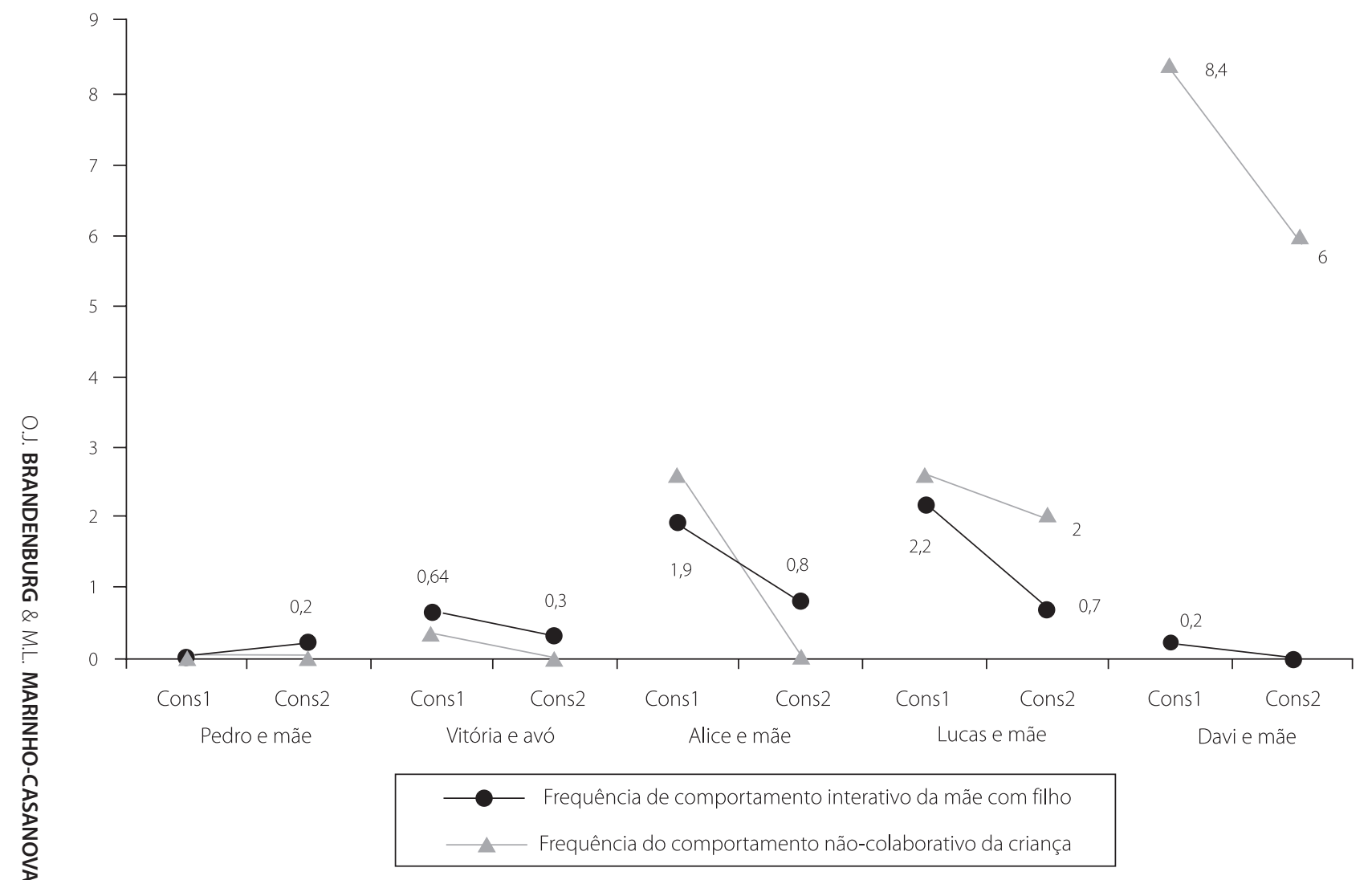

Figura 5. Comportamentos interativos da mãe e comportamentos não colaborativos das crianças na primeira e na segunda consulta. Londrina (PR), 2008.

638

Nota: Cons: Consulta. 
emitidos pela mãe de Alice, podem ter favorecido que as crianças suportassem as estimulações aversivas. Davi praticamente não recebeu apoio nem instrução materna; sua mãe, inclusive, olhou muito pouco para ele. Em um único momento de carinho, em que a mãe acariciou a perna do filho, o choro diminuiu.

A comparação entre as díades Alice/mãe e Davi/ mãe remete aos dados do estudo de Shiota (2004). A autora verificou correlações positivas e significativas: as mães de crianças do grupo de adesão ao tratamento apresentaram maior índice na categoria "carinho", enquanto as mães do grupo de não adesão obtiveram maior índice na categoria "indiferença". Nesse mesmo estudo, Shiota fez análise individual de uma díade de cada grupo e encontrou responsividade na mãe da criança que aderia ao tratamento e permissividade na mãe da criança que não aderia ao tratamento.

A pesquisa apresentada neste artigo alcançou seu objetivo de analisar a relação entre mãe e criança no contexto odontológico. Os dados coletados, ao serem quantificados, demonstraram diferenças entre as díades e possibilitaram análise qualitativa do comportamento infantil de não colaboração. A análise funcional identificou diversas variáveis que podem influenciar o comportamento da criança, dentre elas, o comportamento materno.

Os resultados e as discussões efetuadas sobre os dados dos comportamentos maternos e infantis trazem mais esclarecimentos sobre o fenômeno da não colaboração no dentista, que foi uma contribuição importante da pesquisa descrita. As análises aqui apresentadas foram além da constatação sobre o comportamento de crianças ser ou não afetado pela presença ou a ausência dos pais durante o atendimento, o que já foi bastante explorado na literatura; elas apresentaram algum progresso ao trazerem explicações sobre como ocorre essa influência. As análises funcionais realizadas possibilitam explicar que mães podem exercer função de estímulos antecedentes e consequentes para o comportamento infantil no momento do atendimento odontológico, estabelecendo condições para o comportamento da criança de se autocontrolar e de seguir regras. O entendimento teórico do que ocorre durante uma consulta odontológica com crianças que pouco colaboram vem sendo pouco explorado por parte da comunidade científica e, por isso, a realização de estudos nesse sentido tem grande valor.

Percebe-se o quanto a análise do comportamento contribui para os estudos da área de Odontopediatria a respeito do comportamento não colaborativo infantil. Entende-se que o choro ou os movimentos são comportamentos eliciados ou parte de repertório aprendido em resposta à presença de estimulações aversivas. Tal aprendizado envolve condições ambientais das quais os pais fazem parte. Isso indica que não se pode apenas responsabilizar as crianças por chorarem ou se moverem, rotulando-as como "difíceis" e "teimosas", mas podem-se buscar as relações entre indivíduo e ambiente. Esta é uma visão skinneriana otimista, pois, se a causa não está no interior da criança, e sim nas contingências, então é possível manipular as variáveis para modificar o comportamento. Dentre as variáveis manipuláveis estão os pais, que podem ser instruídos e treinados para agirem de forma mais adequada durante o atendimento odontológico, em benefício à saúde de seu filho.

\section{Referências}

Allen, K. D., Huftless, S., \& Larzelere, R. (2003). Evaluation of two predictors of child disruptive behavior during restorative dental treatment. Journal of Dentistry for Children, 70(3), 221-225

Allen, K. D., Loiben, T., Allen S. J., \& Stanley, R. T. (1992). Dentist implemented contingent escape for management of disruptive child behavior. Journal of Applied Behavior Analysis, 25(3), 629-636.

Allen, K. D., Stark, L. J., Rigney, B. A., Nash, D. A., \& Stokes, T. F. (1988). Reinforced practice of children's cooperative behavior during restorative dental treatment. Journal of Dentistry for Children, 55(4), 273-277.

Allen, K. D., \& Stokes. T. F. (1987). Use of escape and reward in the management of young children during dental treatment. Journal of Applied Behavior Analysis, 20(4), 381-390.

Araújo, S. M., Silveira, E. G., Mello, L.D., Caregnato, M., \& Dal'Asta, V. G. (2010). Ponto de vista dos pais em relação a sua presença durante o atendimento odontológico de seus filhos. Salusvita, 29(2), 17-27.

Brandenburg, O. J., \& Haydu, V. B. (2009). Contribuições da análise do comportamento em odontopediatria. Psicologia Ciência e Profissão, 29(3), 462-475.

Cardoso, C. L., \& Loureiro, S. R. (2008). Estresse e comportamento de colaboração em face do tratamento odontopediátrico. Psicologia em Estudo, 13(1), 133-141. 
Catania, A. C. (1999). Aprendizagem: comportamento, linguagem e cognição. Porto Alegre: Artmed.

Chiesa, M. (1994). Radical behaviorism: The philosophy and the science. Boston: Authors Cooperative.

Fenlon, W. L., Dobbs, A. R., \& Curzon, A. E. J. (1993). Parental presence during treatment of the child patient: A study with British parents. British Dental Journal, 174(1), 23-28.

Fioravante, D. P. \& Marinho-Casanova, M. L. (2009). Comportamento de crianças e de dentistas em atendimentos odontológicos profiláticos e de emergência. Interação em Psicologia, 13(1), 147-154.

Fioravante, D. P., Soares, M. R. Z, Silveira, J. M., \& Zakir, N. S. (2007). Análise funcional da interação profissional-paciente em odontopediatria. Estudos de Psicologia (Campinas), 24(2), 267-277. doi: 10.1590/S0103-166X2007000 200013.

Gross, A. M., Stern, R. M., Levin, R. B., Dale, J., \& Wojnilower, D. A. (1983). The effect of mother-child separation on the behavior of children experiencing A diagnostic medical procedure. Journal of Consulting and Clinical Psychology, 51(5), 783-785.

Johnson, R., \& Baldwin. D. C. (1969). Maternal anxiety and child behavior. Journal of Dentistry for Children, 36(2), 87-92.

Koenigsberg, S. R., \& Johnson, R. (1972). Child behavior during sequential dental visits. Journal of American Dental Association, 85(1), 128-132.

Kotsanos, N., Arhakis, A., \& Coolidge T. (2005). Parental presence versus absence in the dental operatory: A technique to manage the uncooperative child dental patient. European Journal of Paediatric Dentistry, 6(3), 144-148.

Marzo, G., Campanella, V., Albani, F., \& Gallusi, G. (2003). Psychological aspects in paediatric dentistry: Parental presence. European Journal of Paediatric Dentistry, 4(4), 177-180 [Abstract]. Retrieved November 20, 2006, from $<$ http://www.ncbi.nlm.nih.gov/>.

Moraes, A. B. A., \& Pessotti, I. (1985). Psicologia aplicada à odontologia. São Paulo: Sarvier.

Moraes, A. B. A., Sanchez, K. A. S., Possobon, R. F., \& Costa Júnior, A. L. (2004). Psicologia e Odontopediatria: a contribuição da análise funcional do comportamento. Psicologia Reflexão e Crítica, 17(1), 75-82.

Nico, Y. C. (2001). A contribuição de B.F. Skinner para o ensino do autocontrole como objetivo da educação (Dissertação de mestrado não-publicada). Programa de Estudos Pós-graduados em Psicologia Experimental, Pontifícia Universidade Católica de São Paulo.
O'Callaghan, P. M., Allen, K. D., \& Powell, S. (2006). The efficacy of noncontingent escape for decreasing children's disruptive behavior during restorative dental treatment. Journal of Applied Behavior Analysis, 39(2), 161-171.

Possobon, R. F., Moraes, A. B. A., Costa Júnior, A. L., \& Ambrosano, G. M. B. (2003). O comportamento de crianças durante atendimento odontológico. Psicologia: Teoria e Pesquisa, 19(1), 59-64.

Reis, A. A., Teixeira, E. R., \& Paracampo, C. C. P. (2005). Auto-regras como variáveis facilitadoras na emissão de comportamentos autocontrolados: o exemplo do comportamento alimentar. Interação em Psicologia, 9(1), 57-64.

Robey, L. M. (2006). Stress in the dental chair: An investigation of the roles of parental stress and child preparation (Monograph unpublished). St. Mary's College of Maryland, MA. Retrieved April 24, 2007, from <http://www.smcm. edu/psyc/_assets/documents/SMP/Showcase/0506LRobey.pdf $>$.

Rolim, G. S., Moraes, A. B. A., César, J., \& Costa Júnior, A. L. (2004). Análise do comportamento do odontólogo no contexto de atendimento infantil. Estudos de Psicologia (Natal), 9(3), 533-541.

Shiota, C. (2004). Estilos parentais e comportamentos de adesão em crianças com câncer (Dissertação de mestrado não-publicada). Programa Pós-Graduação em Psicologia, Pontifícia Universidade Católica de Campinas.

Skinner, B. F. (1993). Ciência e comportamento humano. São Paulo: Martins Fontes. (Originalmente publicado em 1953).

Tomita, L. M., Costa Junior, A. L., \& Moraes, A. B. A. (2007). Ansiedade materna manifestada durante o tratamento odontológico de seus filhos. Psico-USF, 12(2), 249-256.

Venham, L. L., Murray, P., \& Gaulin-Kremer, E. (1979). Childrearing variables affecting the preschool child's response to dental stress. Journal of Dental Research, 58(11), 2042-2045.

Wright, G. Z., Alpern, G. D., \& Leake, J. L. (1973). The modifiability of maternal anxiety as it relates to children's cooperative dental behavior. ASDC Journal of Dentistry for Children, 40(4), 265-271.

Xia, B., \& Zhang, S. (2012). Effect of pretreatment education of the guardians of children's behavior during dental treatment. Beijing Da Xue Xue Bao; 44(1), 125-9 [Abstract]. Retrieved April 15, 2012, from <http://www.ncbi.nlm. nih. gov/pubmed/22353915>.

Recebido em: 12/9/2012

Versão final em: 10/5/2012

Aprovado em: 28/5/2012 